\title{
Value Co-Creation in Service Recovery: A Combination of Systematic Literature Review and Meta-Analytic Research
}

\author{
Mo Zhang ${ }^{\circledR}$, Shan Jin \\ Economics and Management School, Shanghai Maritime University, Shanghai, China \\ Email: mozhang@shmtu.edu.cn, 68809364@qq.com
}

How to cite this paper: Zhang, M., \& Jin, S. (2020). Value Co-Creation in Service Recovery: A Combination of Systematic Literature Review and Meta-Analytic Research. Journal of Service Science and Management, 13, 388-407.

https://doi.org/10.4236/jssm.2020.132026

Received: December 9, 2019

Accepted: April 26, 2020

Published: April 29, 2020

Copyright $\odot 2020$ by author(s) and Scientific Research Publishing Inc. This work is licensed under the Creative Commons Attribution International License (CC BY 4.0).

http://creativecommons.org/licenses/by/4.0/

\begin{abstract}
Research on value co-creation in service recovery is increasing, yet existing empirical studies show disagreements in their findings. Based on a systemic literature review, we identified 29 articles that investigated 8401 complaint customers in service recovery after value co-creation in this study. Subsequently, a conceptual framework was developed and analyzed through a meta-analysis of 29 independent samples from 26,334 effect sizes. The findings showed that value co-creation is positively associated with post-recovery performance (satisfaction, repurchase intention, and word of mouth) through perceived justice. Moreover, it was found that additional compensation moderates the impact of value co-creation on perceived justice (including procedural justice, distributive justice, and interactional justice). Additionally, the positive relationship between value co-creation and procedural justice is stronger in process service failure than in outcome service failure. The positive impact of value co-creation on interactional justice is amplified in the online service industry. This study contributes to research on value co-creation in service recovery and provides implications for service firms.
\end{abstract}

\section{Keywords}

Service Recovery, Value Co-Creation, Perceived Justice, Meta-Analysis

\section{Introduction}

Value co-creation, which refers to customer engagement in coordinating with employees to complete a service recovery journey (Roggeveen, Tsiros, \& Grewal, 2012), is based on customer participation in service recovery (Dong, Evans, \& Zou, 2008; Vaerenbergh, Hazée, \& Costers, 2018). Service recovery means ac- 
tions taken by companies when service failure happened and he specified it into two dimensions: outcome and process (Gronroos, 1988). In fact, whether engaging in service recovery is an option for the customer (Hogreve, Bilstein, \& Mandl, 2017) and whether to provide the opportunity for the customer to participate in it are strategy choices that service firms must make (Akaka \& Vargo, 2015; Xu, Tronvoll, \& Edvardsson, 2014). As such, value co-creation in service recovery has received close attention from researchers. Existing research has examined various aspects of how it can be conducted, such as considering the level of customer participation (Dong et al., 2008), enhancing resource integration (Xu, Tronvoll, et al., 2014), and empowering complaint customers (Ben-Zur \& Yagil, 2005). Among these studies is research discussing the impact of value co-creation (Cheung \& To, 2016; Hazée, Van Vaerenbergh, \& Armirotto, 2017; Park \& Ha, 2016) on indicators such as satisfaction (Gohary, Hamzelu, \& Alizadeh, 2016; Vázquez-Casielles, Iglesias, \& Varela-Neira, 2017), repurchase intention (Hazée et al., 2017), and word of mouth (Bock, Folse, \& Black, 2016; Zoghbi-Manrique-de-Lara, Suárez-Acosta, \& Aguiar-Quintana, 2014). Some researchers have argued that the approach to take in engaging a customer in participation should depend on the type of service failure involved (Roggeveen et al., 2012). Other researchers have also begun to disentangle the dark side of value co-creation (Haj-Salem \& Chebat, 2014; Heidenreich, Wittkowski, Handrich, \& Falk, 2015), that is if complaint customers fail to achieve value co-creation, they will present more unsatisfied after service recovery. In short, a growing body of research focuses on the effects of value co-creation in service recovery.

Although previous research has provided many insights regarding the reasons that a customer might display willingness to coordinate with a firm and the effects of value co-creation (Koc, Kilic, Bahar, Yumusak, \& Ulukoy, 2015; Nätti, Pekkarinen, Hartikka, \& Holappa, 2014), further research is necessary for two main reasons. First, there are contradictions among the empirical findings of the existing research. In particular, some studies show that value co-creation in service recovery to be positively associated with aspects of performance such as satisfaction and repurchase intention (Dong et al., 2008; Roggeveen et al., 2012), whereas other studies argue that value co-creation buffers the positive impact of service recovery efforts (Hazée et al., 2017; Heidenreich et al., 2015). These conflicting arguments create doubt around the usefulness of value co-creation for service firms and customers. Secondly, researchers view value co-creation as a result of service recovery and examine the impact of this result on customer evaluation in of the service recovery experience (Cheung \& To, 2016; Jin, Nicely, Fan, \& Adler, 2019). In reality, however, value co-creation is a strategy that service firms adopt in service recovery, not a result of it. This means that value co-creation is a service recovery process in itself and that the mechanism of how customers evaluates value co-creation therefore must be researched.

The overall aim of this study is to combine a systematic literature review and a meta-analysis of value co-creation in service recovery in order to explore the 
mechanism of value co-creation's influence on service recovery performance through perceived justice. The findings expand the literature on value co-creation in service recovery and provide meaningful implications for service firms.

\section{Research Framework}

\subsection{Data Coding}

In coding data along the dimension of variables, it can be difficult to ensure that different measures for the same constructs are consistent among primary studies. In a meta-analysis, there is the additional challenge of ensuring the commensurability and heterogeneity of the studies being investigated. For instance, there is an issue related to construct boundaries. The systematic literature review demonstrates that the term "post-recovery performance" has been used broadly in the literature, using a wide range of measurements.

To address this issue, we examined whether the indicators were consistent among the definitions of "post-recovery performance" and confirmed through a discussion among the three authors that $75 \%$ of the items closely match the definition of "satisfaction" after service recovery (Hunter and Schmidt, 2004). The authors first agreed on the definitions for each construct dimension. The reviewed papers were then coded independently to avoid bias, and any disagreements regarding the coding were resolved through discussion. Consequently, we categorized the construct into the relevant dimension of the conceptual framework when more than $75 \%$ of the items in each construct closely matched our definition (Hunter and Schmidt, 2004; Geng, Mansouri and Aktas, 2017).

\subsubsection{Independent Variables}

Existing research has discussed value co-creation based on customer participation in service recovery from two perspectives: value co-creation as a part of the service recovery processes (Boukis, 2016; Jin et al., 2019) and value co-creation as the outcome of service recovery (Elsharnouby \& Mahrous, 2015; Koc et al., 2015; Sugathan, Ranjan, \& Mulky, 2017). In our meta-analysis, we defined value co-creation as a part of the service recovery process, in which customers participate in the recovery as "partial employees" (Dong et al., 2008). The reason we chose this perspective is that value co-creation is a recovery strategy used by service firms that was designed to empower complaining customers to make decisions about how to handle the service failure (Edvardsson, Tronvoll, \& Höykinpuro, 2011; Koc et al., 2015). As a result of this approach, value co-creation influences the customer's perceived justice in service recovery (Balaji, Jha, Sarkar, \& Krishnan, 2018; Guo, Lotz, Tang, \& Gruen, 2016). The definition of value co-creation from a service recovery outcome perspective, meanwhile, is already included in post-recovery performance, as mentioned in next section (Gohary, Hamzelu, Pourazizi, \& Hanzaee, 2016).

\subsubsection{Mediator Variables}

Perceived justice has been well defined in existing research. In equity theory 
(Adams, 1963), it is divided into procedural justice, distributive justice, and interactional justice, with some authors suggesting the addition of informational justice. We adopt the three main dimensions of perceived justice in meta-analysis:

Procedural justice refers to the customer's perception of justice regarding the methods that the firm adopts to deal with the service failure, including policies, procedures, and process controls aimed at fulfilling customer recovery needs (Gohary, Hamzelu, Pourazizi, et al., 2016; Guo et al., 2016). Previous research has suggested flexibility, accessibility, process control, decision control, and responses speed as the sub-dimensions to consider in such discussions (Magnini, 2007).

Distributive justice refers to the individual's perception regarding the tangible resources that the firm uses to rectify a service failure by achieving equitable exchange relationships. In other words, distributive justice is the fairness of service failure management as perceived by complaining customers receiving resources such as discounts, coupons, and monetary refunds (Boukis, 2016; Chen \& Kim, 2019).

Interactional justice focuses on the customer's evaluation of the degree of perceived fairness in interpersonal interaction with the employees who delivered the service recovery (Gohary, Hamzelu, Pourazizi, et al., 2016). Prior research has argued the sub-dimensions of interactional justice include courtesy, offering explanations, and empathy (Cheung \& To, 2016; Xu, Tronvoll, et al., 2014).

\subsubsection{Dependent Variables}

After reviewing the sample of existing studies collected for the meta-analysis, we developed three dimensions to code post-recovery performance: satisfaction with recovery processes, repurchase intention, and word of mouth. Each is defined below.

Satisfaction with recovery processes refers to a complaining customer's positive state of mind and a positive evaluation after the service recovery. Therefore, we coded studies that measured complaining customers' satisfaction with service recovery processes (Authors, 2017; Jin et al., 2019). Measures of satisfaction with recovery processes included indicators of being happy with, pleased with, and grateful for recovery processes (Hamzelu, Gohary, Ghafoori Nia, \& Heidarzadeh Hanzaee, 2017).

Repurchase intention refers to the willingness to or action of repurchase after service recovery (Kuo \& Wu, 2012). Measures of repurchase intention include willingness to repurchase and repurchase behavior after service recovery (Roggeveen et al., 2012).

Word of mouth, in our framework, refers to the willingness of a complaining customer to share information about the service or experience with others in a positive manner. In the meta-analysis, word of mouth included various indicators, such as recommending the service to others and sharing the positive service recovery experience with others (Hamzelu et al., 2017). 


\subsubsection{Moderator Variables}

Moderator variables in meta-analysis are often taken from control variables in existing empirical studies (Golicic and Smith, 2013). As such, these variables affect the zero-order correlation between the independent and dependent variables in the correlational analysis (Hunter and Schmidt, 2004). According to the reviewed papers in this meta-analysis, researchers have emphasized that type of failure, additional compensation, industry, and culture as factors that may influence the relationship between value co-creation and customers' perceived justice (Vaerenbergh et al., 2018). Consequently, moderating variables in our research framework were coded as the below:

Type of service failure can be distinguished by the locus of the failure: process or outcome (Smith et al. 1999). Process failures occur when the service is delivered disrespectfully or the employee is impolite. Outcome failures, such as a canceled flight, occur when the core service is not delivered correctly. Customers have more chances to engage in process failures than in outcome failures and can therefore evaluate the attribution of process failures easily. Thus, customers are more likely to feel that they are participating in service recovery and perceive value co-creation. We expect that the effect size of outcome failure is higher than the process failure.

Additional compensation has been divided into two types: economic compensation (e.g. money) and mental compensation (e.g. apology) (Balaji et al., 2018; Jin et al., 2019; Vaerenbergh et al., 2018). We expect that effect sizes will be higher in studies in which consumers receive additional compensation than in studies in which they simply participate in the service.

Industry is the third moderator variable. The majority of the studies appearing in this meta-analysis were carried out in high-contact service industries, such as the hotel and airline industries. In order to explore the effects of industry on service recovery, given the interactive features of service itself, our meta-analysis divides the industries into two categories: online and offline. An online industry is based on services provided on the platform of the internet and provide self-service to customers or online contact service. For example, the main service failure in an online industry is often payment problems on the self-service online system. By contrast, an offline industry is a traditional service industry in which customers communicate with frontline employees face to face. When service failure occurs, there is less justice bias in offline service industries than in online service ones, as direct interaction with employees leads to rapid responses. Therefore, we expect that the effect size of offline service industries to be lower than that of online ones.

Culture is believed to also play a role. In line with existing literature, this moderator variable captures whether the research data were collected in an Eastern or a Western country. The definition of culture is "the collective programming of the mind, which distinguishes the member of one group of people from others" (Hofstede 1997, p. 9). For instance, customers living in Eastern cultures tend to focus more on relationships and connectedness and have a 
stronger willingness to coordinate with others in their cultural climate than Western customers (Sharama, 2010). We expect higher effect size for studies in Western countries that for studies in Eastern countries. When service failure occurs, Western customers tend to find the solutions by themselves and provide feedback to frontline employees, while customers in Eastern culture do opposite (Vaerenbergh et al., 2018). Thus, we expect that the effect size will be higher in Western culture.

\subsubsection{Control Variables}

In order to ensure the accuracy and consistency of the data, we added three control variables to conduct our meta-analysis: study design, sample, and journal quality.

Study design is based on whether the research methodology is experimental or survey-based. Here, "experiments" refer to scenarios and field study, and "survey" includes interviews, questionnaires, and case studies. The experimental design controls the various variables more objectively, so we anticipate that the experimental effect size will be found to be stronger.

Sample refers to whether respondents are student or nonstudent. Because students have limited experience of everyday life, including customer service, research results based on student data are weighed differently (Burnett and Dune, 1986).

Journal quality captures whether the research is published in an ABS-ranked four-star journal. We use the ABS ranking (2018) as our criterion of journal quality, and four-star journals in ABS ranking (2018) are evaluated as high quality journals. The research published in high-quality journals may report stronger effect sizes than studies published in general journals.

\subsection{Conceptual Framework}

Our systematic literature review found that most of the reviewed papers have mentioned that engaging customers in managing a service failure influences customers' perception in a way that may increase perceived justice $\mathrm{Xu}$, Marshall, Edvardsson, \& Tronvoll, 2014). Therefore, in general, we assume that the influence of value co-creation on customers' perceived justice affects service recovery performance, shown in Figure 1.

First, after value co-creation, consumers judge the compensation in recovery equitable due to their participation in the decision making of the service recovery process, which may influence their sense of distributive justice $(\mathrm{Xu}$, Marshall, et al., 2014). Moreover, when customers have the right to decide how to deal with the service failure, such as choosing the type of compensation, they are more likely to have a positive sense of procedural justice after service recovery (Dong et al., 2008). At the same time, customers' participation enhances their interactional justice because they feel they are being treated fairly when employees ask for their suggestions about the service recovery (Roggeveen et al., 2012). 


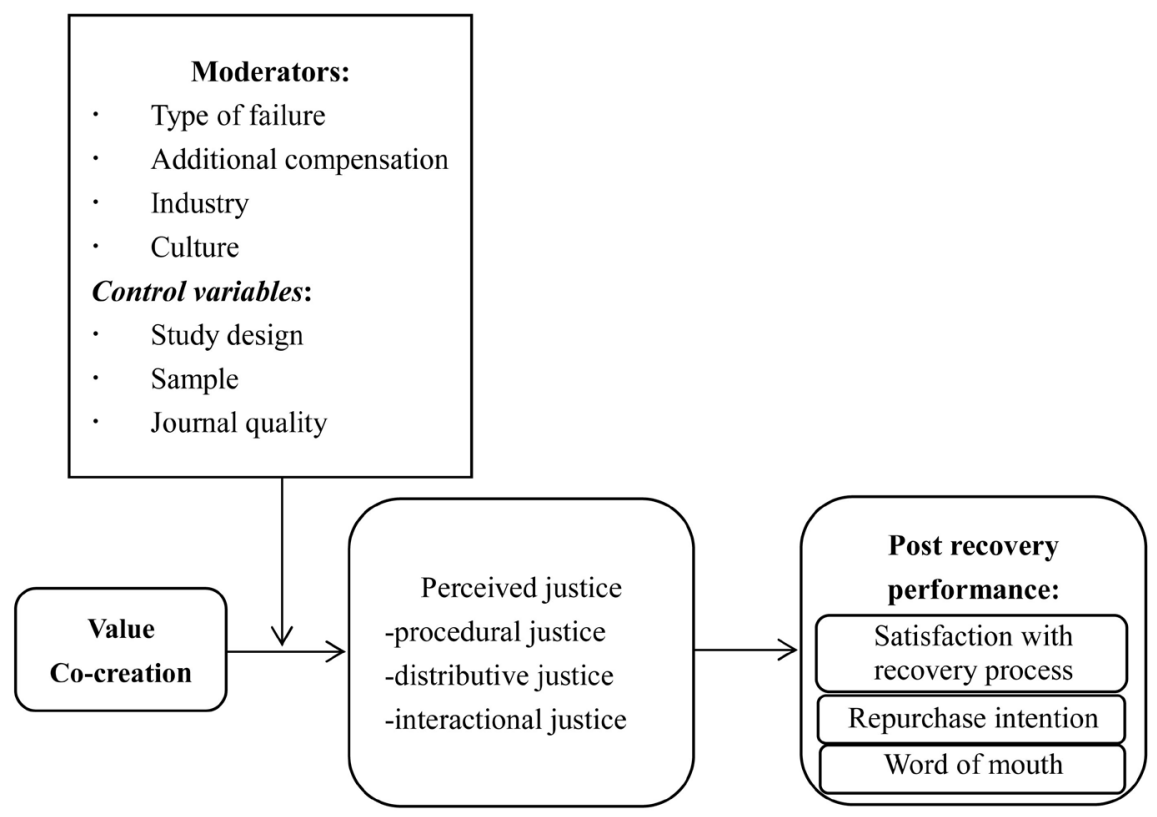

Figure 1. Research framework.

H1. Value co-creation is positively related to customers' perceived justice, including: 1) procedural justice, 2) distributive justice, and 3) interactional justice.

As a service recovery strategy, value co-creation plays as service has positive impact on customer satisfaction, especially after the recovery (Cheung \& To, 2016; Grönroos \& Voima, 2013). We argue that value co-creation is positively related to satisfaction with post-recovery performance, repurchase intention, and word of mouth (Cheung \& To, 2016; Park \& Ha, 2016; Vázquez-Casielles et al., 2017) for three reasons. Firstly, value co-creation creates an appropriate interactional approach between employees and customers that takes into account the customers' needs and preferences, leading to the improvement of procedural justice (Elsharnouby \& Mahrous, 2015). Secondly, the aim of co-creation in service recovery is to increase customer repurchase intention, as customers trust providers who allow them to participate in decision making in the event of a service failure (Boukis, 2016). Consequently, value co-creation is positively associated with distributive justice. Thirdly, customers are satisfied psychologically when employees understand their psychology. In line with this, value co-creation provides customer with opportunities to interact with employees directly, thus leading to interactional justice (Vázquez-Casielles et al., 2017). As summary, we hypothesis as follow:

H2. Value co-creation is positively associated with service recovery performance, including: 1) post-recovery performance, 2) repurchase intention, and 3) word of mouth,

Previous research has revealed that perceived justice has a strong relationship with customer satisfaction in service recovery (Xu, Marshall, et al., 2014). Initially, when customers are willing to participate in value co-creation, they will perceive greater procedural justice and feel satisfied, as they perceive that they 
have some control over the service recovery process (Roggeveen et al., 2012). The customer then receives compensation, which may increase their sense of distributive justice. Having participated in the service recovery process, customers understand the reason for the compensation, thus increasing the satisfaction with recovery (Boukis, 2016; Zhang \& Geng, 2019). Additionally, appropriate interaction with consumers plays an important role in service recovery. Value co-creation provides an opportunity for interaction with customers, including asking for their opinions, leading to an increase the interactional justice (Xu, Marshall, et al., 2014). In summary, we proposed the following hypothesis:

H3. Perceived justice has a positive effect on satisfaction with recovery process.

H3a. Procedural justice has a positive effect on satisfaction with the recovery process.

$H 3$ b. Distributive justice has a positive effect on satisfaction with the recovery process.

H3c. Interactional justice has a positive effect on satisfaction with the recovery process.

Extant research has indicated that when complaining customers focus on the process of service recovery, they are more willing to make future purchases and take part in co-creation in the future (Guo et al., 2016). First, if consumers perceive that they have a dominant role in the process, procedural justice will increase because they will feel that they are needed (Guo et al., 2016). As a result, they become a part of the service provider itself, and their repurchase intention is implied (Hazée et al., 2017; Park \& Ha, 2016). Second, once customers receive compensation that meets their expectations, the repurchase intention will increase as distributive justice is raised (Roggeveen et al., 2012). The reason for this relationship is that customers who perceived distributive justice trust that the service provider is able to deliver high-quality service even in the case of a service failure (Gohary, Hamzelu, \& Alizadeh, 2016; Nadiri, 2016). Third, complaint customers who experience a smooth service recovery and perceive interactive justice tend to choose the same service in the future, thus increasing repurchase intention (Vázquez-Casielles et al., 2017). In short, the following hypothesis is proposed:

H4. Perceived justice has a positive effect on repurchase intention.

H4a. Procedural justice has a positive effect on repurchase intention.

H4b. Distributive justice has a positive effect on repurchase intention.

H4c. Interactional justice has a positive effect on repurchase intention.

Existing research has shown that positive word of mouth plays an important role in service recovery (Ha \& Jang, 2009; Tax, Brown, \& Chandrashekaran, 1998). (On the other hand, when customers feel they have been treated unfairly in service recovery, they tend to spread negative word of mouth.) The first reason for this is that, when customers participate in each part of the process, active word of mouth will be broadcast, owing to the increasement of procedural justice (Vázquez-Casielles et al., 2017). Next, when employees show sympathy to 
customers, the customer, perceiving higher interactional justice, will be more likely to spread word of mouth. Moreover, since material satisfaction is equally as important as psychological satisfaction, consumers may provide free advertising when they receive higher distributive justice (Gohary, Hamzelu, Pourazizi, et al., 2016). Thus, we proposed the following hypothesis:

H5. Perceived justice has a positive effect on word of mouth.

H5a. Procedural justice has a positive effect on word of mouth.

H5b. Distributive justice has a positive effect on word of mouth.

H5c. Interactional justice has a positive effect on word of mouth.

\section{Methods}

\subsection{Literature Search}

In order to investigate how value co-creation impacts post-recovery satisfaction in service recovery, we conducted a systematic review on the existing research on the topic (Henry, Foss, \& Ahl, 2015; Terjesen, Hessels, \& Li, 2016). Searching all papers published until the end of 2018, we first identified five key articles that met our inclusion criteria to create a set of keywords (shown in Table 1) for the following stages of our search. For instance, we applied "customer joint recovery," "co-recovery," and "joint recovery" as the alternative keywords for "value co-creation." In line with this, we kept search terms sufficiently broad to avoid artificial limitations and inaccurate results. Second, we searched several well-known databases: ABI/INFORM, web of science, EBSCO, and Scopus. The identified studies include the search terms in their title, abstract, and keywords. Third, we inspected the references of the identified studies to find further studies on value co-creation in service recovery. These search procedures yielded an initial data set of 60 papers.

\subsection{Inclusion Criteria}

To make sure related papers can be included in the meta-analysis, the articles should met the following three criteria:

1) Focus on service recovery, rather than other recovery, e.g., mental health recovery or industry recovery (52 papers remaining);

Table 1. Keywords sets for the systematic literature review.

\begin{tabular}{ccc}
\hline & & AND \\
\hline Service recovery & Co-creation \\
Service failure & Value creation \\
Failure handing & Value co-creation \\
Compensation & Value co-production \\
Apologize & Creation of value \\
& Customer joint \\
Customer complaint & Co-recovery \\
& Joint recovery \\
\hline
\end{tabular}


2) Focus on service recovery processes that include customer participation (27 papers remaining);

3) The targeted papers needed to report the effect size of the relationships among value co-creation, perceived justice, service recovery performance with Pearson correlation coefficients or other test statistics, such as F-statistics.

Applying these criteria, we identified 29 empirical studies representing a total sample of 8401 customers. These studies are summarized in Table 2.

\subsection{Descriptive Statistics Results}

First, as shown in Figure 2, we analyzed the distribution of the articles' publication dates from 2007 to 2019. The first paper published on our topic was by Karande et al. (2007). The substantial growth trend from 2014 and the eight papers published in 2016 indicate an increased focus in the literature on value co-creation in service recovery. The latest paper published was by Dan Jina et al. (2019).

Next, we divide the industries investigated in the studies into two categories: online industry and offline industry. The "online industry" refers to internet-based companies providing services such as self-service, while the "offline industry" includes traditional, high-contact service companies, such as those in the airline or hotel industry. Figure 3 shows that most of the research under analysis has focused on the offline industry (19 papers). With the increasing development of internet, however, more scholars also investigating the online industry (3 papers), including self-service technology (SST) (Lee \& Cranage, 2018). We then applied the Academic Journal Guide (AJG) as our criterion for the quality of the reviewed papers, as shown in Table 3. The AJG is based on peer review, editorial, and expert judgements on the quality of journals and is updated every three years. As the AJG provides a wide journal coverage and reliable journal quality, it has often been used to identify high-quality papers in systematic literature reviews (Rowlinson et al., (2011); Ashby et al., 2012; Alhejji et al., 2015). Table 3 shows that most of articles we reviewed are published in high-ranking journals, with most articles about co-creation in service recovery published in the Journal of Service Research, the Journal of the Academy of Marketing Science, and the Journal of Retailing and Consumer Services with 3 papers each.

Figure 4 summarizes the type of methodology in the reviewed studies. Scenario (18) and questionnaire (4) were the most common methodologies in the reviewed papers. The scenario method can most faithfully recreate the situation experienced by the participator, leading to the most realistic responses. As a result, the data collected would be more reliable, and subjective errors avoided. A questionnaire, however, is easier to implement than a scenario.

Finally, we investigated the country profile of the studies and categorized them as either Western or Eastern. As can be seen from Figure 5, majority of reviewed papers collected data from Western countries (18), while there were fewer from Eastern countries (7). 
Table 2. Reviewed papers.

\begin{tabular}{|c|c|c|c|c|c|c|c|}
\hline & Authors & Year & Journal Name & Methodology & Industry & Culture & Sample Size \\
\hline 1 & Karande et al. (study 1$)$ & 2007 & Journal of Service Research & scenario & airline & Western & 216 \\
\hline 2 & Karande et al. (study2) & 2007 & Journal of Service Research & scenario & hotel & Western & 208 \\
\hline 3 & Beibei Dong et al. & 2008 & $\begin{array}{c}\text { Journal of the Academy } \\
\text { of Marketing Science }\end{array}$ & scenario & online course & Western & 223 \\
\hline 4 & SALLY A. HIBBERT et al. & 2008 & Journal of Consumer Behavior & scenario & not specified & Western & not specified \\
\hline 5 & Bo Edvardsson et al. & 2011 & Managing Service Quality & interviews & restaurant services & Western & 32 \\
\hline 6 & Roggeveen et al. & 2012 & $\begin{array}{l}\text { Journal of the Academy } \\
\text { of Marketing Science }\end{array}$ & scenario & service companies & Western & 111 \\
\hline 7 & Yingzi Xu et al. & $2014 \mathrm{a}$ & Journal of Service Management & scenario & hospitality industry & Western & 418 \\
\hline 8 & Yingzi Xu et al. & $2014 b$ & Service Industries Journal & scenario & hotel & eastern & 287 \\
\hline 9 & Satu Nätti et al. & 2014 & Industrial Marketing Management & case study & housing corporation & Western & 15 \\
\hline 10 & Sven Heidenreich et al. & 2015 & $\begin{array}{c}\text { Journal of the Academy } \\
\text { of Marketing Science }\end{array}$ & scenario & shoe design & Western & 265 \\
\hline 11 & Elsharnouby, T. H. et al. & 2015 & $\begin{array}{l}\text { Journal of Research } \\
\text { in Interactive Marketing }\end{array}$ & scenario & $\begin{array}{l}\text { telecommunication } \\
\text { sector }\end{array}$ & Eastern & 400 \\
\hline 12 & Erdogan Koca et al. & 2015 & Total Quality Management & scenario & hotel & Eastern & 472 \\
\hline 13 & Achilleas Boukis & 2016 & Service Industries Journal & scenario & travel & Western & 128 \\
\hline 14 & Cheung, F. Y. M. et al. & 2016 & Management Decision & questionnaire & not specified & Eastern & 594 \\
\hline 15 & Park, J. et al. & 2016 & $\begin{array}{l}\text { Journal of Retailing } \\
\text { and Consumer Services }\end{array}$ & scenario & hotel & Western & 330 \\
\hline 16 & Ali Gohary et al. & $2016 a$ & $\begin{array}{l}\text { Journal of Retailing } \\
\text { and Consumer Services }\end{array}$ & scenario & online industry & Eastern & 278 \\
\hline 17 & Ali Gohary et al. & $2016 b$ & $\begin{array}{l}\text { Journal of Retailing } \\
\text { and Consumer Services }\end{array}$ & scenario & bank & Eastern & 944 \\
\hline 18 & $\begin{array}{l}\text { Ali Gohary et al. } \\
\quad(\text { study } 1)\end{array}$ & $2016 c$ & $\begin{array}{l}\text { Journal of Hospitality } \\
\text { and Tourism Management }\end{array}$ & $\begin{array}{c}\text { scenario; } \\
\text { questionnaire }\end{array}$ & travel & Western & 254 \\
\hline 19 & $\begin{array}{l}\text { Ali Goharyet al. } \\
\qquad(\text { study } 2)\end{array}$ & $2016 c$ & $\begin{array}{l}\text { Journal of Hospitality } \\
\text { and Tourism Management }\end{array}$ & $\begin{array}{c}\text { scenario; } \\
\text { questionnaire }\end{array}$ & travel & Western & 188 \\
\hline 20 & $\begin{array}{l}\text { Dong, B et al. } \\
\quad(\text { study } 1)\end{array}$ & 2016 & Journal of Service Research & scenario & car rental & Western & 92 \\
\hline 21 & $\begin{array}{l}\text { Dong, B et al. } \\
\quad(\text { study } 2)\end{array}$ & 2016 & Journal of Service Research & scenario & car rental & Western & 439 \\
\hline 22 & Guo et al. & 2016 & Journal of Service Research & questionnaire & cable service & Western & 283 \\
\hline 23 & Vazquez-Casielles et al. & 2017 & Service Business & $\begin{array}{l}\text { interviews; } \\
\text { scenario }\end{array}$ & $\begin{array}{l}\text { department store; } \\
\text { computer store }\end{array}$ & Western & 240 \\
\hline 24 & $\begin{array}{c}\text { Simon Hazée et al. } \\
\text { (study } 1)\end{array}$ & 2017 & Journal of Business Research & scenario & airline & Western & 464 \\
\hline 25 & $\begin{array}{c}\text { Simon Hazée et al. } \\
(\text { study } 2)\end{array}$ & 2017 & Journal of Business Research & scenario & hotel & Western & 466 \\
\hline 26 & Joosten et al. & 2017 & Journal of Service Management & questionnaire & not specified & Eastern & 260 \\
\hline 27 & Praveen Sugathan et al. & 2017 & Journal of Interactive Marketing & scenario & bicycle design & Western & 112 \\
\hline 28 & M.S. Balaji et al. & 2018 & Journal of Business Research & scenario & hotel & Western & 187 \\
\hline 29 & Dan Jina et al. & 2019 & $\begin{array}{l}\text { Journal of Hospitality } \\
\text { and Tourism Management }\end{array}$ & scenario & hotel & Western & 495 \\
\hline
\end{tabular}




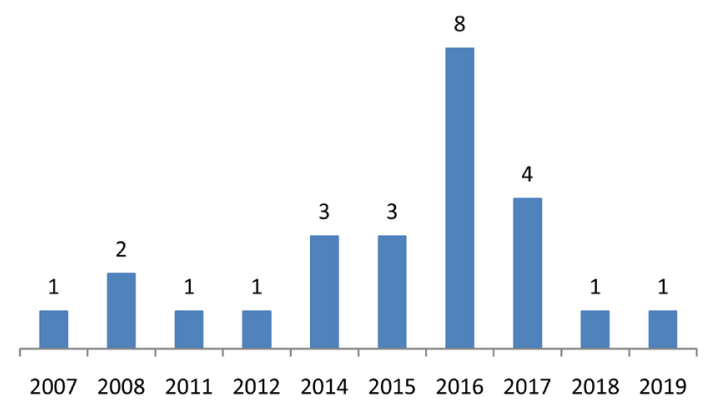

Figure 2. Distribution of reviewed papers across the period 2007-2019.

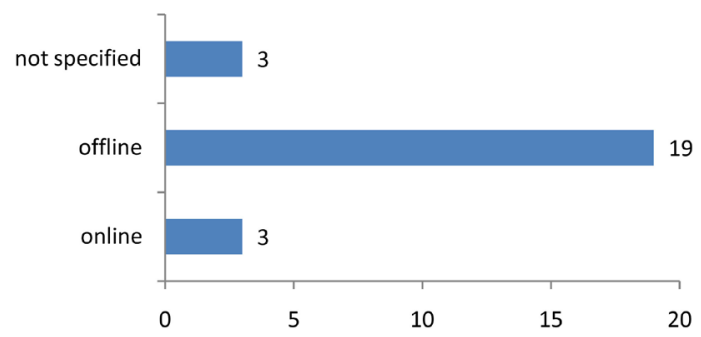

Figure 3. Industry distribution of papers reviewed.

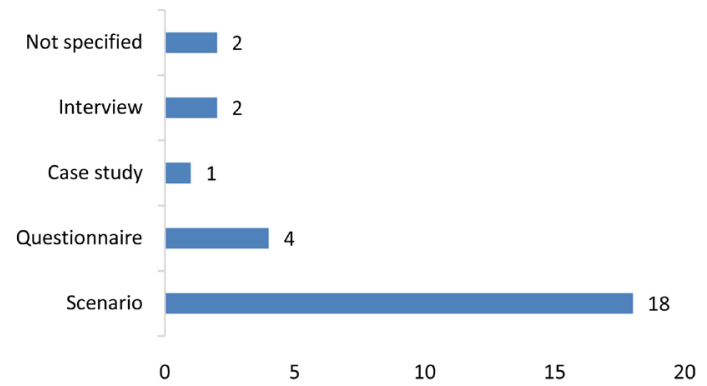

Figure 4. Number of papers by methodology.

Table 3. Number of papers by journal.

\begin{tabular}{cccc}
\hline Journal name & $\begin{array}{c}\text { Number of } \\
\text { articles }\end{array}$ & $\begin{array}{c}\text { AJG (ABS) } \\
\text { ranking 2018 }\end{array}$ & $\begin{array}{c}\text { Percentage } \\
(\%)\end{array}$ \\
\hline Journal of Service Research & 3 & 4 & 12 \\
Journal of the Academy of Marketing Science & 3 & $4^{*}$ & 12 \\
Journal of Retailing and Consumer Services & 3 & 2 & 12 \\
Journal of Service Management & 2 & NA & 8 \\
Service Industries Journal & 2 & 2 & 8 \\
Journal of Business Research & 2 & NA & 8 \\
Journal of Hospitality and Tourism Management & 2 & 1 & 8 \\
Industrial Marketing Management & 1 & 3 & 4 \\
Total Quality Management & 1 & NA & 4 \\
Journal of Research in Interactive Marketing & 1 & 1 & 4 \\
Management Decision & 1 & NA & 4 \\
Journal of Consumer Behavior & 1 & 2 & 4 \\
Service Business & 1 & NA & 4 \\
Managing Service Quality & 1 & 1 & 4 \\
Journal of Interactive Marketing & 1 & NA & 4 \\
\hline
\end{tabular}




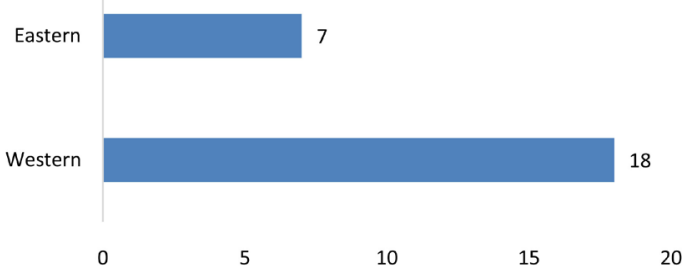

Figure 5. Number of papers by culture.

\subsection{Meta-Analysis Process}

\subsubsection{Meta-Analysis}

Following Hunter and Schmidt (2004), we use meta-analysis to discern the accuracy of the relationships proposed above and generalize the empirical results of previous studies (Raudenbush et al., 1991). We used a fixed-effects meta-analysis, an approach found to be effective in similar studies, and the software Comprehensive Meta-Analysis. To begin the meta-analysis, we used corrected average correlation of each variable. If a paper did not report a reliability variable, we use mean sample size-weighted reliability variable in its place. We then reported the standard errors, 95\% confidence intervals and other significance tests, such as Q-value, Z-value, and P-value. We also reported the fail-safe $\mathrm{N}$, which indicates the necessary number of null studies for significant relationships.

\subsubsection{Moderator Analysis}

Additionally, for further statistical information, we tested the predictions in Figure 5 again. To test for significance, we chose Q-value of each hypothesis to do a meta-regression and the result is reported in Table 4 . We reported the parameter estimate, standard error, and P-value of every study to determine which moderator variable may be present. Because the overall variable has difference with detailed variables, so report all these significance values.

\section{Result}

The results we provide will be presented in two steps. First, the descriptive statistics regarding the relationship between the value co-creation and perceived justice and its outcome variables are included in Meta-analysis results. Second, we report the moderator analysis results.

\subsection{Meta-Analysis Results}

We employed the software Comprehensive Meta-Analysis to simply operations. The result is shown in Table 4, where $\mathrm{K}$ refers to the number of studies, $\mathrm{N}$ refers to the sample size, and $\mathrm{R}$ refers to the average correlations during the studies. According to Cohen and Cohen (1983) and Cohen et al. (2003), an effect size less than 0.1 is weak, $0.1-0.3$ is moderate, and higher than 0.3 is strong. Therefore, in Table 3, value co-creation positively and strongly affects perceived justice, including procedural justice $(\mathrm{r}=0.355, p=0.000)$, distributive justice $(\mathrm{r}=$ 
Table 4. Result of meta-analysis.

\begin{tabular}{|c|c|c|c|c|c|c|c|c|c|c|}
\hline $\begin{array}{l}\text { FIXED } \\
\text { model }\end{array}$ & $\mathrm{K}$ & $\mathrm{N}$ & $\begin{array}{c}\text { Effect size } \\
(\mathrm{r})\end{array}$ & $\begin{array}{r}95 \\
\text { Confi } \\
\text { Interv }\end{array}$ & $\begin{array}{l}\% \\
\text { lence } \\
\text { l of } r\end{array}$ & $\begin{array}{l}\text { Standard } \\
\text { error }\end{array}$ & Q-Statistic & $\begin{array}{c}\mathrm{Z} \\
\text { value }\end{array}$ & $\begin{array}{c}\mathrm{P} \\
\text { value }\end{array}$ & $\begin{array}{c}\text { Fail-safe } \\
\quad \mathrm{N}\end{array}$ \\
\hline \multicolumn{11}{|c|}{ H1: Value co-creation - Perceived justice } \\
\hline H1a PJ & 6 & 2589 & 0.355 & 0.052 & 0.321 & 0.389 & 129.547 & 18.844 & 0.000 & 616 \\
\hline H1b DJ & 6 & 2589 & 0.459 & 0.045 & 0.428 & 0.489 & 113.569 & 25.163 & 0.000 & 860 \\
\hline $\mathrm{H} 1 \mathrm{c} \mathrm{IJ}$ & 6 & 2589 & 0.251 & 0.043 & 0.215 & 0.287 & 107.955 & 13.018 & 0.000 & 259 \\
\hline \multicolumn{11}{|c|}{$\mathrm{H} 2$ : Value co-creation - Service recovery performance } \\
\hline $\mathrm{H} 2 \mathrm{aSA}$ & 9 & 3087 & 0.474 & 0.138 & 0.447 & 0.501 & 619.534 & 28.534 & 0.000 & 2184 \\
\hline $\mathrm{H} 2 \mathrm{~b} \mathrm{RI}$ & 7 & 2028 & 0.340 & 0.069 & 0.301 & 0.378 & 178.578 & 15.872 & 0.000 & 420 \\
\hline $\mathrm{H} 2 \mathrm{c}$ WOM & 1 & 240 & 0.303 & 0.023 & 0.267 & 0.403 & 5.409 & 8.966 & 0.000 & \\
\hline \multicolumn{11}{|c|}{ H3: Perceived justice - Satisfaction } \\
\hline H3a PJ & 4 & 2076 & 0.722 & 0.324 & 0.700 & 0.742 & 508.192 & 41.385 & 0.000 & 1928 \\
\hline H3b DJ & 6 & 2500 & 0.754 & 0.560 & 0.736 & 0.770 & 1471.251 & 48.922 & 0.000 & 3820 \\
\hline $\mathrm{H} 3 \mathrm{c} \mathrm{IJ}$ & 5 & 2363 & 0.782 & 0.624 & 0.766 & 0.797 & 1384.938 & 50.903 & 0.000 & 3145 \\
\hline \multicolumn{11}{|c|}{ H4: Perceived justice - Repurchase intention } \\
\hline $\mathrm{H} 4 \mathrm{a} \mathrm{PJ}$ & 3 & 1333 & 0.609 & 0.311 & 0.574 & 0.641 & 163.138 & 25.719 & 0.000 & 639 \\
\hline $\mathrm{H} 4 \mathrm{~b} \mathrm{DJ}$ & 3 & 1333 & 0.534 & 0.401 & 0.495 & 0.572 & 210.309 & 21.686 & 0.000 & 510 \\
\hline $\mathrm{H} 4 \mathrm{c} \mathrm{IJ}$ & 3 & 1333 & 0.757 & 0.346 & 0.734 & 0.779 & 181.543 & 36.030 & 0.000 & 789 \\
\hline \multicolumn{11}{|c|}{ H5: Perceived justice - Word of mouth } \\
\hline H5a PJ & 2 & 538 & 0.715 & 0.005 & 0.671 & 0.754 & 0.081 & 20.713 & 0.000 & \\
\hline H5b DJ & 2 & 538 & 0.772 & 0.005 & 0.736 & 0.804 & 0.326 & 23.655 & 0.000 & \\
\hline $\mathrm{H} 5 \mathrm{c} \mathrm{IJ}$ & 2 & 538 & 0.567 & 0.252 & 0.507 & 0.622 & 47.426 & 14.839 & 0.000 & \\
\hline
\end{tabular}

DJ: distributive justice; PJ: procedural justice; IJ: interactional justice; SA: satisfaction with post-recovery; RI: repurchase intention; WOM: word of mouth.

$0.459, p=0.000)$. While interactional justice is positively related to value co-creation $(\mathrm{r}=0.251, p=0.000)$, the effect size is weaker than that of the others. Thus, H1 is supported. Next, value co-creation is strongly associated with post-recovery performance, including satisfaction with recovery process $(\mathrm{r}=$ $0.474, p=0.000)$, repurchase intention $(\mathrm{r}=0.34, p=0.000)$, and word of mouth $(\mathrm{r}=0.303, p=0.000)$. As such, $\mathrm{H} 2$ is supported as well.

Moreover, perceived justice affects post-recovery performance significantly and positively. The effect sizes of the three perceived justice dimensions' impact on satisfaction with recovery processes are higher than 0.5 , including procedural justice $(\mathrm{r}=0.754, p=0.000)$, distributive justice $(\mathrm{r}=0.722, p=0.000)$, and interactional justice $(\mathrm{r}=0.782, p=0.000)$. Thus, $\mathrm{H} 3$ is supported. Similar to post-recovery satisfaction, distributive justice $(\mathrm{r}=0.772, p=0.000)$ and procedural justice $(r=0.715, p=0.000)$ have a positive effect on word of mouth, while interactional justice have a weaker effect than word of mouth $(\mathrm{r}=0.567, p=$ $0.000)$. Moreover, interactional justice $(\mathrm{r}=0.757, p=0.000)$ is significant for repurchase intention, while procedural justice $(\mathrm{r}=0.609, p=0.000)$ and distributive justice $(\mathrm{r}=0.534, p=0.000)$ are a little weaker. Thus, H4 and H5 was supported. 


\subsection{Moderator Analysis Results}

Table 5 shows the moderator analysis results. $\mathrm{R}^{2}$ represents the reliability of statistics. The reliabilities are all higher than 99\%, meaning that the three types of perceived justice are strongly reliable, and significance F shows its validity. The results indicate that procedural justice (0.131) and interactional justice (0.149) are not significant in the moderating role. Additional compensation has positive moderate the relationships between value co-creation and distributive justice $(\gamma$ $=0.77, p<0.1)$, procedural justice $(\gamma=0.79, p<0.1)$, and interactional justice $(\gamma$ $=0.78, p<0.1)$, which means if the service firm gives customers additional compensation in the process of value co-creation, the customer will perceive greater fairness. Type of failure negatively moderates the relationship between value co-creation and procedural justice $(\gamma=-0.64, p<0.1)$. Meantime, the positive impact of value co-creation on interactional justice is amplified in the case of online industry $(\gamma=1.29, p<0.1)$. It was found that, whether in Western or Eastern cultures, customers feel almost the same levels of perceived justice in value co-creation. Regarding the control variables, the effect sizes are all similar.

Table 5. Moderator analysis results.

\begin{tabular}{|c|c|c|c|}
\hline Variables & $\begin{array}{c}\text { Parameter } \\
\text { estimate }\end{array}$ & $\begin{array}{l}\text { Standard } \\
\text { error }\end{array}$ & $P$ value \\
\hline \multicolumn{4}{|c|}{ Distributive justice; $R^{2}=99.65(\%) ;$ Significance $F=0.088$} \\
\hline Type of failure ( $0=$ process failure, $1=$ outcome failure $)$ & -0.02258 & 0.057678 & 0.762408 \\
\hline Additional compensation $(0=$ no, $1=$ yes $)$ & 0.772644 & 0.057678 & 0.047436 \\
\hline Industry $(0=$ offline, $1=$ online $)$ & 0.372036 & 0.076301 & 0.128779 \\
\hline Culture $(0=$ eastern, $1=$ western $)$ & -0.03252 & 0.076301 & 0.743477 \\
\hline Study design ( $0=$ survey, $1=$ experiment $)$ & 0.378024 & 0.474463 & 0.509156 \\
\hline Sample $(0=$ non-student, $1=$ student $)$ & 0.022584 & 0.547862 & 0.970863 \\
\hline Journal quality $(0=$ not elite, $1=$ elite $)$ & -0.069395 & 0.474463 & 0.897126 \\
\hline \multicolumn{4}{|c|}{ Procedural justice; $\mathbf{R}^{2}=99.23(\%) ;$ Significance $F=0.131$} \\
\hline Type of failure $(0=$ process, $1=$ outcome $)$ & -0.6355 & 0.100591 & 0.09994 \\
\hline Additional compensation $(0=$ no, $1=$ yes $)$ & 0.785455 & 0.100591 & 0.081089 \\
\hline Industry ( $0=$ offline, $1=$ online $)$ & 0.161063 & 0.13307 & 0.439594 \\
\hline Culture $(0=$ eastern, $1=$ western $)$ & 0.58433 & 0.13307 & 0.142547 \\
\hline Study design $(0=$ survey, $1=$ experiment $)$ & -0.01110 & 0.48492 & 0.983810 \\
\hline Sample $(0=$ non-student, $1=$ student $)$ & 0.635497 & 0.55994 & 0.374104 \\
\hline Journal quality $(0=$ not elite, $1=$ elite $)$ & -0.28283 & 0.48492 & 0.618729 \\
\hline \multicolumn{4}{|c|}{ Interactional justice; $R^{2}=99.0(\%) ;$ Significance $F=0.149$} \\
\hline Type of failure ( $0=$ process failure, $1=$ outcome failure $)$ & 0.316309 & 0.121159 & 0.232876 \\
\hline Additional compensation $(0=$ no, $1=$ yes $)$ & 0.778099 & 0.121159 & 0.098339 \\
\hline Industry ( $0=$ offline, $1=$ online $)$ & 1.293214 & 0.160278 & 0.078501 \\
\hline Culture $(0=$ eastern, $1=$ western $)$ & -0.45169 & 0.160278 & 0.217077 \\
\hline Study design $(0=$ survey, $1=$ experiment $)$ & -0.19881 & 0.482228 & 0.720133 \\
\hline Sample $(0=$ non-student, $1=$ student $)$ & -0.31631 & 0.556829 & 0.627270 \\
\hline Journal quality $(0=$ not elite, $1=$ elite $)$ & 0.768787 & 0.482228 & 0.251918 \\
\hline
\end{tabular}




\section{Conclusion}

Our meta-analysis about the value co-creation is focused on service recovery. The results of this research revealed some relationship between value co-creation and post recovery performance according to perceived justice. Firstly, to identify the research framework, we do a data coding. Secondly, through some systematic literature review, we identified 29 empirical studies representing a total sample of 8,401 customers. Then, the results of meta-analysis and moderator analysis show that in service recovery process, the value co-creation can positively affect post recovery performance through the effect of perceived justice. And if the firm provides addition compensation, the customer will feel more justified. Overall, the adoption of value co-creation in service recovery will play an increasingly important role in service companies.

\subsection{Theoretical and Managerial Implications}

The overall aim of this research was to consolidate the existing empirical findings regarding the impact of value co-creation from complaining customers in service recovery on post-recovery performance through customers' perceived justice. Our systematic literature review and meta-analysis offer the following contributions.

First, this research outlines the influence of value co-creation through interactions between customers and frontline employees on post-recovery performance (including satisfaction with recovery process, repurchase intention, and word of mouth). Our study complements Vaerenbergh et al.'s (2018) meta-analysis, focused on customer participation and its effects on service recovery. Both studies found that additional compensation in service recovery moderates the positive impact of value co-creation on perceived justice. Thus, this study reaffirmed the moderating role of additional compensation in service recovery (Kwon \& Jang, 2012; Noone, 2012; Vaerenbergh et al., 2018). However, our study also found that the type of failure moderated the relationship between value co-creation and procedural justice, while the effect of value co-creation on interactional justice is stronger in the online service industry. As such, this study has expanded the existing research on value co-creation in a service recovery context.

Second, our research treats customers' perceived justice as the mechanism of value co-creation impact on post-recovery performance, while previous research treated it as an outcome of the service recovery journey (Vaerenbergh, Varga, \& Keyser, 2019). However, value co-creation involves the customers themselves engaging in the process of managing a service failure and thus influences the perceived justice reflected in their post-recovery satisfaction. In line with this idea, this research explored how value co-creation, as a service recovery strategy, may influence customers' evaluations of service recovery outcomes. In other words, we address the recent call for more research on the impact of value co-creation in service recovery and whether engaging in service recovery is an option for complaint customers. Some research suggests a dark side of value 
co-creation in service recovery, especially in cases of failure, that is if customer failed to achieve value co-creation in service recovery, they display even more unsatisfied. The results of this study are consistent with recent research on this dark side of customer participation in service recovery (Heidenreich et al., 2015) and provide a mechanism through which customers display even more dissatisfaction after engaging in service recovery. As such, we provide insights into the integrated empirical findings reported in the existing literature.

In summary, this study analyzed value co-creation as a strategy in service recovery and examined its impact on service recovery performance through perceived justice by combining the methods of a systematic literature review and a meta-analysis.

\subsection{Limitations}

There are several limitations of this study that may be addressed in further research. First, due to the limitation of meta-analysis, its conceptual framework only addressed the constructs used in previous studies. Therefore, constructs such as perceived control (Guchait, Kim, \& Namasivayam, 2012), psychological safety (Guchait, Paşamehmetoğlu, \& Dawson, 2014), and self-efficacy of customer (Dong, Sivakumar, Evans, \& Zou, 2016) were not included in this study. Second, the results of this meta-analysis were based on a systematic literature review, and empirical research confirming them has yet to be conducted.

\section{Acknowledgements}

This work was supported by the National Natural Science Foundation of China (Grant No. 71702099) and Foundation of Shanghai Science \& Technology (Grant No. 19692104800). The funding sources had no involvement in the study design, the data collection, analysis, and interpretation of the data, or in the decision to submit the article for publication.

\section{Conflicts of Interest}

The authors declare no conflicts of interest regarding the publication of this paper.

\section{References}

Akaka, M. A., \& Vargo, S. L. (2015). Extending the Context of Service: From Encounters to Ecosystems. Journal of Services Marketing, 29, 453-462. https://doi.org/10.1108/JSM-03-2015-0126

Authors, F. (2017). Consumer Control in Service Recovery: Beyond Decisional Control.

Balaji, M. S., Jha, S., Sarkar, A., \& Krishnan, B. C. (2018). Are Cynical Customers Satisfied Differently? Role of Negative Inferred Motive and Customer Participation in Service Recovery. Journal of Business Research, 86, 109-118. https://doi.org/10.1016/j.jbusres.2018.01.023

Ben-Zur, H., \& Yagil, D. (2005). The Relationship between Empowerment, Aggressive Behaviours of Customers, Coping, and Burnout. European Journal of Work and Orga- 
nizational Psychology, 14, 81-99. https://doi.org/10.1080/13594320444000281

Bock, D. E., Folse, J. A. G., \& Black, W. C. (2016). When Frontline Employee Behavior Backfires: Distinguishing between Customer Gratitude and Indebtedness and Their Impact on Relational Behaviors. Journal of Service Research, 19, 322-336.

https://doi.org/10.1177/1094670516633754

Boukis, A. (2016). Achieving Favourable Customer Outcomes through Employee Deviance. Service Industries Journal, 36, 319-338. https://doi.org/10.1080/02642069.2016.1219722

Chen, P., \& Kim, Y. G. (2019). Role of the Perceived Justice of Service Recovery: A Comparison of First-Time and Repeat Visitors. Tourism and Hospitality Research, 19, 98-111. https://doi.org/10.1177/1467358417704885

Cheung, F. Y. M., \& To, W. M. (2016). A Customer-Dominant Logic on Service Recovery and Customer Satisfaction. Management Decision, 54, 2524-2543. https://doi.org/10.1108/MD-03-2016-0165

Dong, B., Evans, K. R., \& Zou, S. (2008). The Effects of Customer Participation in Co-Created Service Recovery. Journal of the Academy of Marketing Science, 36, 123-137. https://doi.org/10.1007/s11747-007-0059-8

Dong, B., Sivakumar, K., Evans, K. R., \& Zou, S. (2016). Recovering Coproduced Service Failures: Antecedents, Consequences, and Moderators of Locus of Recovery. Journal of Service Research, 19, 1-16. https://doi.org/10.1177/1094670516630624

Edvardsson, B., Tronvoll, B., \& Höykinpuro, R. (2011). Complex Service Recovery Processes: How to Avoid Triple Deviation. Managing Service Quality: An International Journal, 21, 331-349. https://doi.org/10.1108/09604521111146234

Elsharnouby, T. H., \& Mahrous, A. A. (2015). Customer Participation in Online Co-Creation Experience: The Role of e-Service Quality. Journal of Research in Interactive Marketing, 9, 313-336. https://doi.org/10.1108/JRIM-06-2014-0038

Gohary, A., Hamzelu, B., \& Alizadeh, H. (2016a). Please Explain Why It Happened! How Perceived Justice and Customer Involvement Affect Post Co-Recovery Evaluations: A Study of Iranian Online Shoppers. Journal of Retailing and Consumer Services, 31, 127-142. https://doi.org/10.1016/j.jretconser.2016.03.013

Gohary, A., Hamzelu, B., \& Pourazizi, L. (2016c). A Little Bit More Value Creation and a Lot of Less Value Destruction! Exploring Service Recovery Paradox in Value Context: A Study in Travel Industry. Journal of Hospitality and Tourism Management, 29, 189-203. https://doi.org/10.1016/j.jhtm.2016.09.001

Gohary, A., Hamzelu, B., Pourazizi, L., \& Hanzaee, K. H. (2016b). Understanding Effects of Co-Creation on Cognitive, Affective and Behavioral Evaluations in Service Recovery: An Ethnocultural Analysis. Journal of Retailing and Consumer Services, 31, 182-198. https://doi.org/10.1016/j.jretconser.2016.03.016

Gronroos, C. (1988). Service Quality: The Six Criteria of Good Perceived Service Quality. Review of Business, 9, 10-13.

Grönroos, C., \& Voima, P. (2013). Critical Service Logic: Making Sense of Value Creation and Co-Creation. Journal of the Academy of Marketing Science, 41, 133-150. https://doi.org/10.1007/s11747-012-0308-3

Guchait, P., Kim, M. G., \& Namasivayam, K. (2012). Error Management at Different Organizational Levels: Frontline, Manager, and Company. International Journal of Hospitality Management, 31, 12-22. https://doi.org/10.1016/j.ijhm.2011.04.007

Guchait, P., Paşamehmetoğlu, A., \& Dawson, M. (2014). Perceived Supervisor and Co-Worker Support for Error Management: Impact on Perceived Psychological Safety 
and Service Recovery Performance. International Journal of Hospitality Management, 41, 28-37. https://doi.org/10.1016/j.ijhm.2014.04.009

Guo, L., Lotz, S. L., Tang, C., \& Gruen, T. W. (2016). The Role of Perceived Control in Customer Value Cocreation and Service Recovery Evaluation. Journal of Service Research, 19, 39-56. https://doi.org/10.1177/1094670515597213

Haj-Salem, N., \& Chebat, J. C. (2014). The Double-Edged Sword: The Positive and Negative Effects of Switching Costs on Customer Exit and Revenge. Journal of Business Research, 67, 1106-1113. https://doi.org/10.1016/j.jbusres.2013.05.050

Hamzelu, B., Gohary, A., Ghafoori Nia, S., \& Heidarzadeh Hanzaee, K. (2017). Does Involvement Shapes Consumers' Response to Product Failure? Asia Pacific Journal of Marketing and Logistics, 29, 283-304. https://doi.org/10.1108/APJML-03-2016-0042

Hazée, S., Van Vaerenbergh, Y., \& Armirotto, V. (2017). Co-Creating Service Recovery after Service Failure: The Role of Brand Equity. Journal of Business Research, 74, 101-109. https://doi.org/10.1016/j.jbusres.2017.01.014

Heidenreich, S., Wittkowski, K., Handrich, M., \& Falk, T. (2015). The Dark Side of Customer Co-Creation: Exploring the Consequences of Failed Co-Created Services. Journal of the Academy of Marketing Science, 43, 279-296.

https://doi.org/10.1007/s11747-014-0387-4

Henry, C., Foss, L., \& Ahl, H. (2015). Gender and Entrepreneurship Research: A Review of Methodological Approaches. International Small Business Journal: Researching Entrepreneurship, 34, 217-241. https://doi.org/10.1177/0266242614549779

Hogreve, J., Bilstein, N., \& Mandl, L. (2017). Unveiling the Recovery Time Zone of Tolerance: When Time Matters in Service Recovery. Journal of the Academy of Marketing Science, 45, 866-883. https://doi.org/10.1007/s11747-017-0544-7

Jin, D., Nicely, A., Fan, A., \& Adler, H. (2019). Joint Effect of Service Recovery Types and Times on Customer Satisfaction in Lodging. Journal of Hospitality and Tourism Management, 38, 149-158. https://doi.org/10.1016/j.jhtm.2019.01.005

Koc, E., Kilic, R., Bahar, R., Yumusak, S., \& Ulukoy, M. (2015). The Influence of Customer Participation on Service Failure Perceptions. Total Quality Management \& Business Excellence, 28, 390-404. https://doi.org/10.1080/14783363.2015.1090290

Kwon, S. Y., \& Jang, S. C. S. (2012). Effects of Compensation for Service Recovery: From the Equity Theory Perspective. International Journal of Hospitality Management, 31, 1235-1243. https://doi.org/10.1016/j.ijhm.2012.03.002

Lee, B., \& Cranage, D. A. (2018). Causal Attributions and Overall Blame of Self-Service Technology (SST) Failure: Different from Service Failures by Employee and Policy. Journal of Hospitality Marketing and Management, 27, 61-84. https://doi.org/10.1080/19368623.2017.1337539

Magnini, V. P. (2007). Recovery Voice and Satisfaction after Service Failure AN Experimental Investigation of Mediating and Moderating Factors. Journal of Service Research, 10, 187-203.

Nadiri, H. (2016). Diagnosing the Impact of Retail Bank Customers' Perceived Justice on Their Service Recovery Satisfaction and Post-Purchase Behaviours: An Empirical Study in Financial Centre of Middle East. Economic Research Ekonomska Istrazivanja, 29, 193-216. https://doi.org/10.1080/1331677X.2016.1164925

Nätti, S., Pekkarinen, S., Hartikka, A., \& Holappa, T. (2014). The Intermediator Role in Value Co-Creation within a Triadic Business Service Relationship. Industrial Marketing Management, 43, 977-984. https://doi.org/10.1016/j.indmarman.2014.05.010

Noone, B. M. (2012). Overcompensating for Severe Service Failure: Perceived Fairness 
and Effect on Negative Word-of-Mouth Intent. Journal of Services Marketing, 26, 342-351. https://doi.org/10.1108/08876041211245254

Park, J., \& Ha, S. (2016). Co-Creation of Service Recovery: Utilitarian and Hedonic Value and Post-Recovery Responses. Journal of Retailing and Consumer Services, 28, 310-316. https://doi.org/10.1016/j.jretconser.2015.01.003

Roggeveen, A. L., Tsiros, M., \& Grewal, D. (2012). Understanding the Co-Creation Effect: When Does Collaborating with Customers Provide a Lift to Service Recovery? Journal of the Academy of Marketing Science, 40, 771-790. https://doi.org/10.1007/s11747-011-0274-1

Sugathan, P., Ranjan, K. R., \& Mulky, A. G. (2017). Atypical Shifts Post-Failure: Influence of Co-Creation on Attribution and Future Motivation to Co-Create. Journal of Interactive Marketing, 38, 64-81. https://doi.org/10.1016/j.intmar.2017.01.002

Terjesen, S., Hessels, J., \& Li, D. (2016). Comparative International Entrepreneurship: A Review and Research Agenda. Journal of Management, 42, 299-344. https://doi.org/10.1177/0149206313486259

Vaerenbergh, Y., Van Varga, D., \& De Keyser, A. (2019). The Service Recovery Journey: Conceptualization, Integration, and Directions for Future Research the Service Recovery Journey: Conceptualization, Integration, and Directions for Future Research. Journal of Service Research, 22, 103-119. https://doi.org/10.1177/1094670518819852

Vaerenbergh, Y., Van, Hazée, S., \& Costers, A. (2018). Customer Participation in Service Recovery: A Meta-Analysis. Marketing Letters, 29, 465-483. https://doi.org/10.1007/s11002-018-9470-9

Vázquez-Casielles, R., Iglesias, V., \& Varela-Neira, C. (2017). Co-Creation and Service Recovery Process Communication: Effects on Satisfaction, Repurchase Intentions, and Word of Mouth. Service Business, 11, 321-343. https://doi.org/10.1007/s11628-016-0311-8

Xu, Y., Marshall, R., Edvardsson, B., \& Tronvoll, B. (2014a). Show You Care: Initiating Co-Creation in Service Recovery. Journal of Service Management, 25, 369-387. https://doi.org/10.1108/JOSM-11-2012-0253

Xu, Y., Tronvoll, B., \& Edvardsson, B. (2014b). Recovering Service Failure through Resource Integration. Service Industries Journal, 34, 1253-1271. https://doi.org/10.1080/02642069.2014.942652

Zhang, M., \& Geng, R. (2019). Empowerment in Service Recovery: The Role of Self-Regulation Process of Frontline Employee. Management Decision, 58, 828-843. https://doi.org/10.1108/MD-10-2018-1073

Zoghbi-Manrique-de-Lara, P., Suárez-Acosta, M. A., \& Aguiar-Quintana, T. (2014). Hotel Guests' Responses to Service Recovery: How Loyalty Influences Guest Behavior. Cornell Hospitality Quarterly, 55, 152-164. https://doi.org/10.1177/1938965513513348 